\title{
EL TESTIMONIO EN LA FICCIÓN: REPRESENTACIONES DE LA VIOLENCIA EN LA NOVELISTICA COLOMBIANA
}

Por:

\author{
Kevin Alexis García
}

Docente de la Escuela de Comunicación Social

Universidad del Valle

kevimaster@gmail.com

\section{Resumen:}

Este trabajo presenta un análisis crítico acerca del testimonio y la memoria histórica que sobre la violencia en Colombia de la segunda mitad del siglo XX ha propuesto la novelística nacional. Toma como muestras las obras Leopardo al sol, Angosta, La virgen de los sicarios, La lectora, El Divino, Cartas cruzadas, El cronista y el espejo y Rosario Tijeras. En ellas, mediante un análisis comparativo analiza continuidades, rupturas, conexiones y diálogos que a su vez entran en relación con el discurso que la historiografía ha construido de nuestros conflictos. Una cartografía literaria, un testimonio en la ficción.

Palabras claves: Violencia partidista, literatura, historiografía de la violencia, ficción narrativa.

\begin{abstract}
:
This work shows a critical analysis about the testimony and the historical memory that, about the violence in Colombia of second half of twentieth century, the national fiction has proposed. It take as samples the works Leopardo al sol, Angosta, La virgen de los sicarios, La lectora, El Divino, Cartas Cruzadas, El cronista y el espejo y Rosario Tijeras. In these novels, through a comparative analysis are studied continuities, breaks, connections and dialogues which, in turn, are related with the discourse that historiography has made about our conflicts. A literary cartography, a testimony of the fiction.
\end{abstract}

Key words: partisan violence, literature, historiography of violence, narrative fiction. 
En el marco de los estudios sobre novela y violencia, con el objetivo de trazar perspectivas sobre la representación histórica en nuestra narrativa, este trabajo propone una cartografía crítica a partir de la lectura transversal a ocho novelas colombianas. Un abordaje a estas obras podría hacerse desde la escogencia de una temática común en ellas. Podría analizarse la representación de la ciudad desde la mirada de los diversos autores, o así mismo, la recreación de las provincias y las particularidades de sus violencias y duelos; también el mutuo influjo entre los escenarios geográficos. Podría hacerse un análisis comparativo de la temática atinente exclusivamente al narcotráfico; algunos estudios han profundizado con acierto en la representación ficcional del sicariato como argumento central de las obras literarias. Un abordaje interesante es el que Clausewitz llama "fricciones", los efectos no esperados desencadenados por el combate (no sólo referido a la selva), el desencadenamiento de las pasiones y los odios entre los actores, todo lo que diferencia la guerra real de la guerra teórica y que escapa al conocimiento común de la violencia.

No obstante los senderos mencionados, es mi interés en este texto, acorde con indagaciones anteriores, realizar un análisis comparado de las obras literarias en el marco histórico de un contexto de violencia mayor. De acuerdo con Daniel Pecaut, -autor que será clave en este trabajo por su indagación sistemática y rigurosa del conflicto colombiano-, la expansión de la economía de la droga será fundamental para comprender la segunda ola de violencia desatada en Colombia en el último cuarto del siglo XX. El auge del narcotráfico y sus dineros en el país fueron fundamentales para la duplicación de los frentes de las FARC y para la profesionalización de su ejército, durante la primera mitad de los años ochenta; así mismo, para la conformación de los ejércitos paramilitares, para las bandas criminales urbanas, para el surgimiento del sicariato y otras modalidades de agrupaciones delincuenciales. En ese contexto, la construcción de un corpus literario sobre la violencia, sectorizado por actores, modalidades económicas o de otro tipo, siempre encontrará fronteras difusas, zonas oscuras y prácticas mixtas. El factor seleccionado para el análisis será la instancia de representación preponderante en cada autor, su perspectiva de abordaje. Me interesa analizar qué aspectos seleccionan los novelistas para la construcción de sus ficciones, cuáles son los escenarios escogidos, los actores caracterizados, los intereses recreados, los recursos para el ejercicio de la violencia, las redes de poder y los conflictos que plantean; esto en confrontación con los hechos históricos. Las obras escogidas sobre la temática permiten reconstruir una cartografía de la violencia en Colombia, principalmente, en el último cuarto del siglo XX. Es necesario también revisar cómo los autores resuelven la tensión de construir hechos de gran trascendencia social en un universo literario propio.

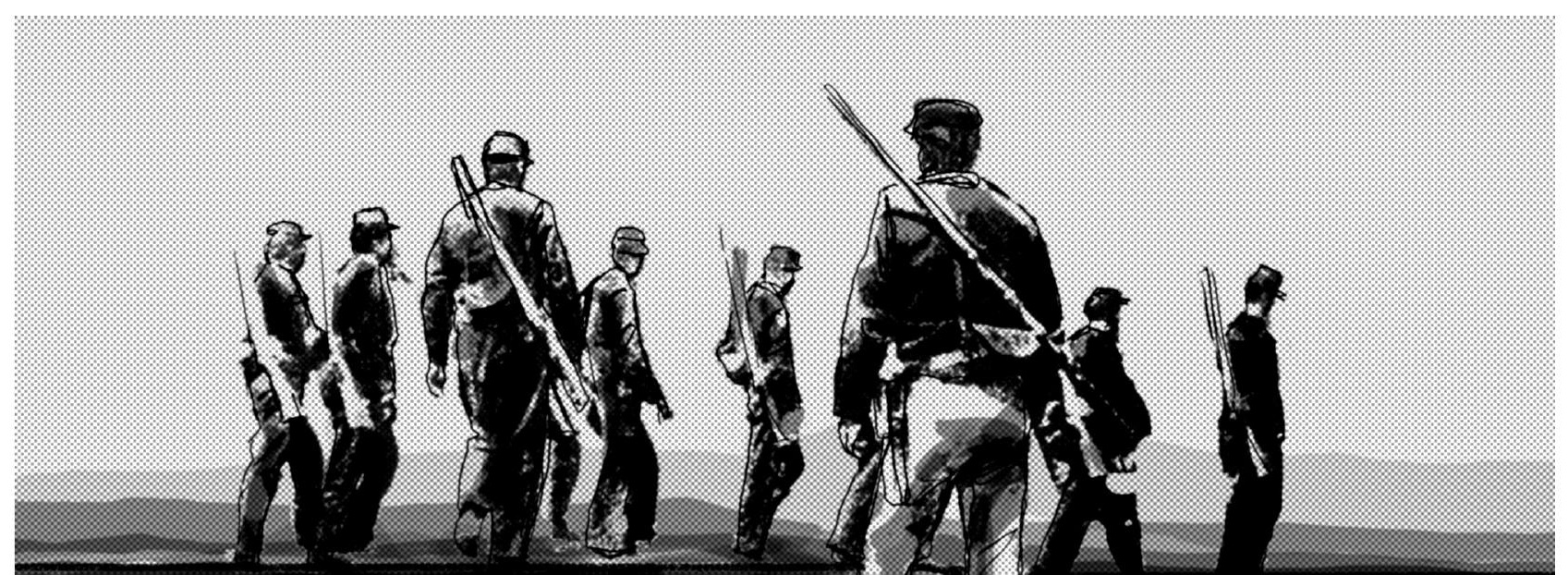


Intentaré hacer cruces y comparaciones entre las novelas de acuerdo con sus temáticas, no por el orden de publicación, pues es sabido que no hay una correlación entre los años en que se divulgan las ficciones y los hechos históricos que abordan. Entre las obras escogidas, La Virgen de los Sicarios de Fernando Vallejo (1994) y Rosario Tijeras de Jorge Franco (1999) abordan ambas el fenómeno del sicariato en Medellín y cinco años diferencian sus fechas de publicación. En Leopardo al sol Laura Restrepo (1993) y Héctor Abad Faciolince en Angosta (2003) proponen ambos síntesis estructurales de múltiples violencias y la segunda obra se publicó una década después que la primera. El Divino de Gustavo Álvarez Gardeazábal (1986) y El cronista y el espejo de Óscar Osorio (2006) coinciden en representar, de distinta forma, el impacto del narcotráfico en el Valle del Cauca, siendo conocida la segunda dos décadas después que la primera. En las dos obras restantes para nuestro abordaje, Darío Jaramillo aborda en Cartas cruzadas el fenómeno del narcotráfico en Antioquia y Sergio Álvarez en La lectora la mafia y la violencia en Bogotá (2000).

Una primera característica de esta narrativa consiste en que en ella los autores ya no buscan plasmar valores morales como lo hizo gran parte de la literatura colombiana desde finales de siglo XIX y primera mitad del XX. Tampoco se observan enardecidas ideologías, vindicación de causas revolucionarias o de partidos políticos, como se percibía en algunas obras literarias de la Violencia ${ }^{1}$ partidista. La contemporánea conforma una literatura del desencanto y del descreimiento que parece desligarse, paulatinamente, de las aprehensiones moralistas y de los prejuicios y estigmas de las clases dominantes.

Los autores contemporáneos han leído la historia, han aprendido de sus predecesores y en sus obras los partidos políticos tradicionales ya no representan subculturas ciudadanas; ahora abordan la cultura del sicariato como una subcultura del narcotráfico (Pecaut, 2001:123). No se percibe la presión ideológica de la iglesia católica. Se comprende que, como decía Juan José Saer, "el sentido de una novela, enemigo de toda pasividad, se proyecta y se expande desde el pasado hasta el porvenir, ramificándose en él y produciendo cambios fundamentales en la conciencia de ciertos hombres" (1997:237). Esta novelística construye una memoria históricaficcional de nuestros tiempos. En medio de las diferencias de enfoques, hechos y momentos históricos recreados, las obras se unen en un elemento común: la exacerbada violencia, la soberanía de la fuerza bruta.

Me interesa indagar si los autores logran construir una visión interna o externa de los fenómenos, si logran definir hipótesis en medio de la narración y qué metáforas y visiones de mundo plasman. Las violencias acontecidas en Colombia son de una complejidad susceptible para proponer diversas maneras de interpretación. Los enfoques estructurales comprenden las acciones violentas a partir de las estructuras sociales en que se gestan. Los enfoques individualistas buscan explicar la violencia a partir de las particularidades de los actores que las cometen. Sin embargo, una mirada de equilibrio propondrá no polarizar los enfoques individual y social. Un reconocimiento de los elementos comunes entre las novelas, permitirá identificar las características estructurales de la violencia, así como las particularidades de los múltiples personajes construidos en estos entornos narrativos.

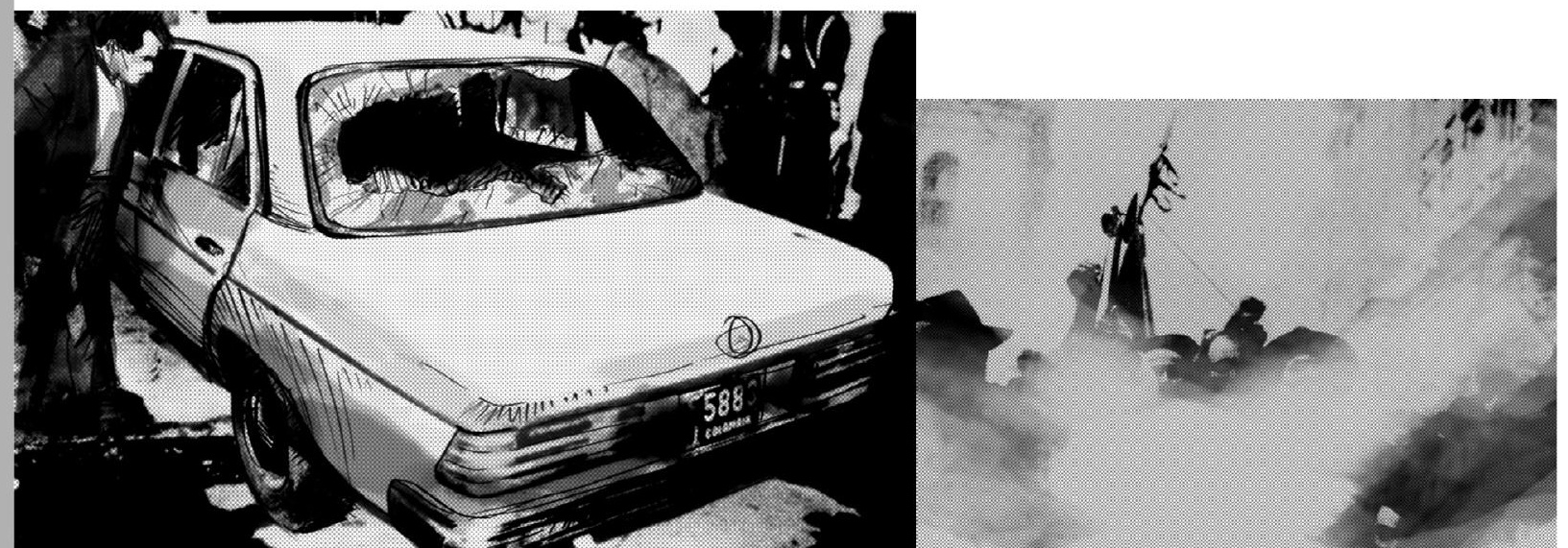


Las obras plasman la violencia institucional, la violencia política, la violencia económica y simbólica, la exclusión, la tortura, el desarraigo, la ambición desmesurada y la muerte. Elementos distintivos de la agitación social de las últimas décadas del siglo XX en Colombia.

\section{El surgimiento de la economía de la droga}

Después de la llamada Violencia partidista expandida aproximadamente entre 1946 y 1965, se gesta la violencia asociada al despegue de la economía de la droga. Para Daniel Pecaut han comenzado estas hostilidades a comienzos de los años setenta, ligadas al cultivo de la marihuana que se daba en la Costa Atlántica desde finales de la década anterior. Las presiones de Estados Unidos sobre Jamaica, Turquía y México, sus principales proveedores de droga, propiciaron el surgimiento del negocio en las naciones del Tercer mundo. "En Colombia, el gobierno concentraba sus Fuerzas Armadas en la persecución a los grupos guerrilleros y vastos territorios carecían de una presencia del Estado. Regiones como la Sierra Nevada de Santa Marta, reunían una diversidad de climas ideales para el cultivo y una ruta de exportación por el mar Caribe. Se formaron organizaciones locales para el envío de marihuana en Santa Marta y la Guajira. Éste último había sido utilizado durante décadas para el contrabando de mercancías extranjeras que ingresaban al país sin pagar tributos. Contaba con numerosos puertos, bahías, caletas y una población acostumbrada al comercio clandestino. En poco tiempo la producción y envío de drogas alucinógenas demostró que podía dejar más ganancias que cualquier mercancía” (García, 2007:92).

En el país se generó una bonanza económica que no tributaba en las arcas del Estado y demandó un tráfico organizado que establecía acuerdos de comercialización, sistemas de embarque especializados, métodos de transporte, redes para la corrupción de las autoridades y el consentimiento de los grupos insurgentes. Pero la burocratización y competencia de los traficantes marimberos fueron generando vendettas entre familias de la Guajira, que desencadenaron en olas de violencia en las ciudades del Caribe.

Leopardo al sol se centra en este momento histórico. Laura Restrepo recrea los conflictos de la Guajira, departamento que reunía varias particularidades, pues el recrudecimiento de la violencia marimbera fue nutrido por las rivalidades tradicionales entre los clanes de poder. Abordaré con mayor detenimiento esta obra con respecto a las demás para identificar en ella los elementos claves del fenómeno del narcotráfico.

Restrepo construye una novela compleja, producto de once años de investigación. Exhibe en cada párrafo un gran sentido de la composición literaria. En la obra el clan de los Barragán, liderado por Nando y el clan Monsalve, liderado por Mani, se enfrentan en una guerra de décadas por el exterminio mutuo de la familia enemiga. Se construye así la narrativa de una violencia de clanes entre familias contrabandistas, provincianas, poderosas, violentas, ricas, emergentes y desmesuradas.

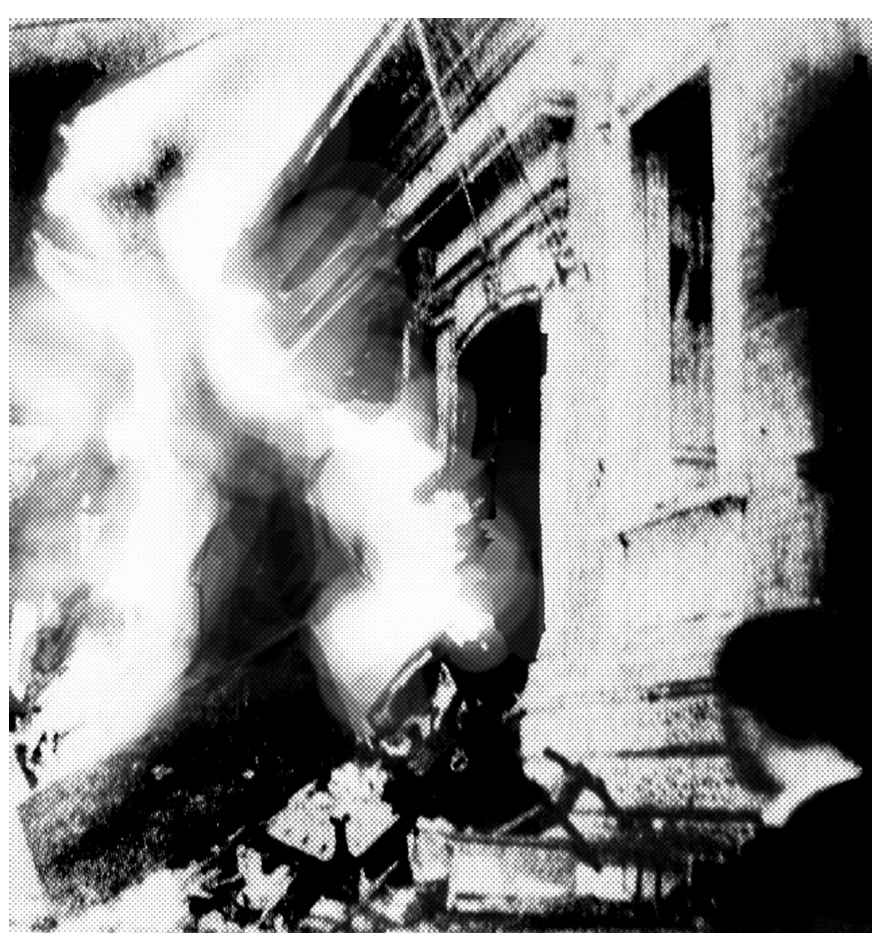


A los Barragán en la ciudad los odian, los adulan, los repudian y los imitan. De Nando se dice que a su paso sólo quedan viudas y huérfanos. Él y su familia practican el asesinato sistemático bajo los principios éticos Wayúu. Los Barragán y los Monsalve han convertido en una cuestión de honor el arte de la venganza. La obra exhibe el control de la población en que los clanes ejercen la violencia y el contrabando:

La caravana de cuatro automóviles pasa zumbando, volando bajito, por las calles de la ciudad. Una Silverado y tres Toyotas cuatro puertas de placas venezolanas. Despedidos como ráfagas, chirriando $\mathrm{y}$ quemando llantas, ostentando bellaquería y armamento, mordiendo el andén en las esquinas, mansalveando el tránsito, ignorando los semáforos, haciendo saltar estudiantes de maleta, salpicando agua de charco sobre las mujeres que compran leche, metiendo pánico en los voceadores de lotería, en los perros de la plaza (1993:45).

Los Monsalve y los Barragán se van exterminando mutuamente, los hombres de cada familia saben que morirán en su ley, que "esos son los gajes del oficio". Para las familias marimberas contrabandistas la muerte está presupuestada, se le evita pero se sabe que llegará. Además de la violencia, Laura Restrepo recrea en la obra los caminos posibles de estos clanes delincuenciales. Los Barragán, desbordados en la suntuosidad y el despilfarro, van perdiendo poco a poco sus riquezas y poder. Por su parte, los Monsalve logran sostener sus negocios, mediante el lavado de sus dineros en empresas legales que contaban con la inversión y el respaldo clandestino de la élite empresarial de la ciudad.

La novela recrea las tensiones de la nueva clase emergente por instalarse en la clase dominante, en la alcurnia que controlaba el poder político y social. Esto lo vemos en Mani, un personaje complejo, atroz y sensible, obstinado en legalizar la fortuna de la familia mediante su inserción en la alta sociedad:

Mani quiere integrarse a un mundo moderno, urbano, donde la ilegalidad y la violencia fluyen por debajo como caños de aguas negras mientras en la superficie brillan los cocteles de smoking, los acuerdos de beneficio mutuo con altos mandos militares; las mujeres hermosas que gastan fortunas en ropa; los bautismos oficiados obispos; los tratos de tú a tú con políticos prominentes; las oficinas impactantes con empleados de cuello blanco y las inversiones en sociedades abiertas y cerradas. (1993:82).

Mani logra, gracias a su dinero, instaurarse en la clase que repudia y que a su vez lo seduce. La obra recrea la doble moral de las élites de la costa, la corrupción de las institucionales oficiales, los cálculos estratégicos de la población para alinearse en favor de uno u otro bando y procurar la protección. Se recrea bajo un telón de permanentes asesinatos y torturas.

Se plasma en Leopardo al sol la definición que de la violencia hace Pecaut como un fenómeno social presente en las sociedades, un recurso alternativo y de uso frecuente para resolver diferencias, para imponer intereses o puntos de vista. 
La violencia de las familias es efectuada mediante un cuidadoso código de ética que fija el género de las víctimas (hombres), las fechas (conmemoraciones de muertes) y las formas de matar (de frente al enemigo para que pueda defenderse).

Para Pecaut, con la economía de la droga, los fenómenos de violencia en Colombia ya no obedecen a un contexto inicial, pues están en permanente transformación y produciendo a su vez nuevos contextos. La violencia se percibe en Leopardo al sol como una tendencia duradera, obedece a lógicas estratégicas, fundadas en el uso de la fuerza. La racionalidad cultural del conflicto de clanes se rompe cuando los Monsalve desean exterminar rápidamente a la familia Barragán para dedicarse al negocio del contrabando. Deciden para ello romper el código ético y contratar otras personas para que maten por ellos.

Allí aparece Holman Fernely, un ciudadano común, adusto y parco, experto en el crimen, un sicario a sueldo, desvinculado de los pactos de las familias en disputa, sin ningún principio ético para actuar y con el único objetivo de asesinar a sus víctimas, lo que le da una gran eficiencia en la delincuencia; aparece como una de las primeras expresiones del sicariato.

La obra de Laura Restrepo construye en un universo propio una memoria histórica del surgimiento de la economía de la droga, de sus primeras manifestaciones de violencia, de la transición entre el tráfico de la marihuana al de la cocaína, de la primeras conformaciones de grupos paramilitares y sicarios, contratados para matar a sueldo y brindar protección a los jefes y sus familias. También es memoria de las fricciones entre las clases emergentes y las dominantes, de la corrupción de las instituciones del Estado y de las autoridades locales.

En Leopardo al sol se representan elementos constantes y estructurales de la degradación social propiciada por el narcotráfico a partir de los años setenta y de las múltiples violencias que se generan, en deterioro de la población civil y sus instituciones. En los inicios de la producción de la pasta de coca, en Latinoamérica también se producía en países como Perú y mayoritariamente en Bolivia. Sin embargo, fue en nuestro país donde se consolidaron los laboratorios para su procesamiento y se crearon las rutas para la exportación. En estos dos últimos procesos es donde la droga adquiere su mayor valor y ellos propiciaron la conformación de pequeños narcotraficantes, asociados en carteles que operaban, principalmente, como centros de exportación.

Los fenómenos sociales de principios y mediados de siglo acontecidos en Colombia también se habían presentado en otros países latinoamericanos. Entre estos la explosión demográfica, la incipiente revolución industrial y la concentración de la riqueza en las ciudades industrializadas, el abandono de los pequeños poblados, la crisis económica en las provincias, los desplazamientos, la explosión y transformación de las grandes ciudades y las tensiones entre ciudadanos normalizados y advenedizos rurales. La imitación de formas de vida entre los nuevos desconocidos de la urbe, la insurrección de masas, el surgimiento de caudillos populistas, de posteriores dictadores y la intromisión directa de los ejércitos en el poder ejecutivo. Sin embargo, nuestro país se caracterizaría a lo largo del siglo por una violencia crónica que afectaría todas sus estructuras. 
La producción y comercialización de la marihuana dejó unos saberes adquiridos para el negocio de la cocaína. El poder del narcotráfico, la violencia como recurso para el sometimiento de las poblaciones y la precariedad del Estado propiciaron la degradación social. En la visión de mundo que se construye en Leopardo al sol no se siente una presencia fuerte de la Violencia partidista sobre las prácticas de las guerras entre clanes. Lo anterior se comprende, considerando que, a diferencia del resto del país, en la Costa Atlántica no se vivió su atrocidad.

Para Pecaut la memoria de la Violencia contribuye de múltiples maneras, a que la nueva violencia no sorprenda, a que aparezca como "normal", a que se difunda también fácilmente, a que sus dimensiones y sus retos inéditos no sean percibidos sino tardíamente.

Por su parte, las novelas El cronista y el espejo, y El divino, sí recrean la influencia de la Violencia sobre las guerras del narcotráfico y el sicariato. En la obra de Óscar Osorio, Nebrio, un temible sicario es hijo de un ex integrante de los Pájaros, las bandas conservadoras auspiciadas en forma clandestina por el Partido azul para exterminar a liberales y conservatizar los municipios del Valle del Cauca. Osorio construye en Nebrio un personaje siniestro que para comprenderlo será fundamental recordar el legado de violencia que hereda de su padre: violencia física y simbólica. Ambas novelas abordan la presencia del narcotráfico en el Valle del Cauca.

En El divino, Gustavo Álvarez Gardeazábal (1986) aborda esta presencia en el municipio de Ricaurte y alcanza una narración desde adentro que no escapa a la fatigación del vano misticismo, el chismerío y la superstición, propios de la vida en algunos pueblos. Los personajes recuerdan permanentemente las marcas de la Violencia partidista. En el recorrido que hacen Héctor Aquiles, Epifanía y Benedicta hacia Ricaurte pasan por el puente que despierta sus recuerdos:

Este puente era de piso de tabla y cuando comenzó la violencia tiraban los muertos al río para que los recogieran en Cartago o en La Virginia. Era horrible... se los veía pasar flotando, con un gallinazo encima. (1986:69).

En El divino, Gardeazábal se interesa por recrear las vicisitudes sucedidas en Ricaurte cuando Mauro, uno de sus habitantes alcanza la prosperidad económica, a través de los dineros del contrabando, causando un revuelo a su llegada al pueblo. El autor se interesa por poner en paralelo el retorno de otra pareja que ha alcanzado el éxito por el camino largo y angosto de la vida honrada. Vemos entonces la extravagante seducción por el primero, su capacidad de disponer sobre las fiestas del pueblo, su ostentación monetaria y las constantes peregrinaciones que realizan los habitantes hasta su casa para pedirle ayuda.

Lo anterior opera como una metáfora para comprender que los narcotraficantes legitimaron sus prácticas frente a los sectores sociales de menores ingresos. Mientras el Estado declaraba ilegal el tráfico de cocaína, los narcos demostraban en sus comunidades que era posible forzar el destino, el porvenir de la miseria o la pobreza permanente y que podía adquirirse una riqueza rápida y monumental. 
Ejerciendo la filantropía del derroche y cierta solidaridad de la ostentación, los narcos contaban con una base social, sumisa y admiradora de sus poderes.

Por otra parte, en El cronista y el Espejo Óscar Osorio se acerca a la violencia a través del descenso que realiza Óskar Alexis, un brillante profesor universitario, que, en busca de mayor distinción profesional, contacta a un excompañero de la universidad para conocer a través de él la vida de los narcos y los suburbios de la criminalidad. El autor se interesa por mostrar como las prácticas ligadas con el mundo narco afectaron todas las instancias de la sociedad y subvirtieron los valores y la ética. Construido en una relación especular con Nebrio, Óskar desciende hasta los submundos de la delincuencia en la que termina inmiscuyéndose poco a poco, hasta convertirse en testigo y cómplice de las torturas propias del oficio criminal:

Se tomó un trago (Machete) mientras los otros le abrían la boca al hombre y le estiraban la lengua con un alicate. El machete desprendió un pingajo sangrante... Nebrio se paralizó. (74)

Pecaut sostiene que en Colombia la violencia se ha naturalizado y ya no es percibida como un acto extremo y recurrente de aniquilamiento de la vida y sus expresiones, sino como una práctica sistemática y sofisticada para la adquisición y sostenimiento del poder. Esto es representado en la obra de Osorio. Las torturas practicadas por los Pájaros en la época partidista, es repetida por Nebrio como por herencia familiar. Pero a diferencia de la época de la Violencia, en la actual ya no se encuentra la división amigo-enemigo. La expansión de la economía de la droga ha provocado en vastos sectores la atomización de la sociedad civil, la sumisión y la disuasión, mediante todo tipo de masacres.

Los narcotraficantes sólo requerían establecer formas de control social sobre las regiones, bajo la complicidad de las autoridades locales y de los barones electorales que, amparados por el narcotráfico, terminaban ocupando los cargos públicos. Nebrio, siendo un reconocido profesor universitario, termina convertido en el autor intelectual de un crimen, cómplice de torturas y asesinatos y atado a la muerte de su macabro amigo. Sin embargo, se había inmiscuido en estos mundos no con el propósito de integrarlos, sino de retractarlos para la obtención de su prestigio intelectual. Escindido, confrontado con su propia conciencia a lo largo de la historia, termina atrapado en el hampa.

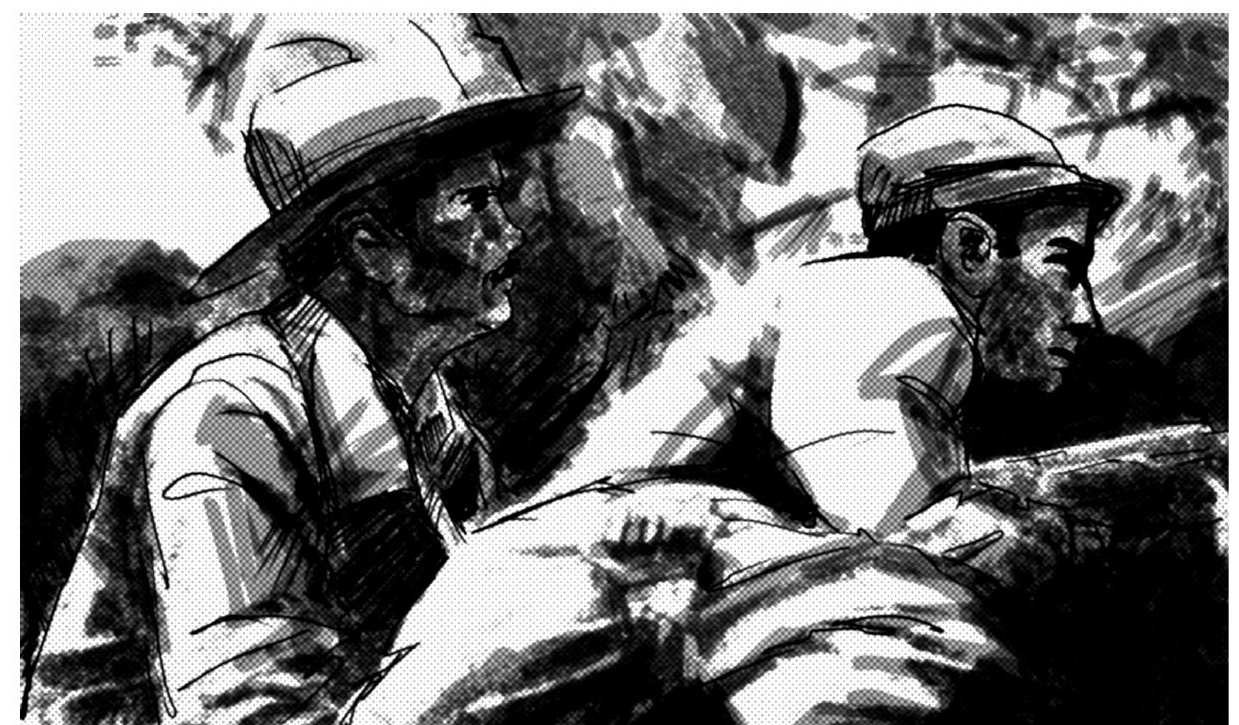


Situación distinta sucede con Luis, el personaje de Cartas cruzadas, la obra de Darío Jaramillo. En medio del creciente aumento de su prestigio intelectual de profesor universitario, este personaje termina seducido por la vida que posibilita las riquezas del narcotráfico. No termina en ese mundo por accidente, lo hace por decisión. Darío Jaramillo recurre al procedimiento epistolar y mediante las cartas que se escriben durante diez años los personajes principales, construye un fresco de la decadencia de los valores antioqueños, de la fascinación de las élites económicas por los dineros ilegales, de la corrupción general de la sociedad. En la obra Esteban, amigo de Luis, opera como una conciencia moral que advierte sobre los futuros conflictos ligados con la consecución del dinero fácil. Paulatinamente, Luis empieza a pagar el precio de estar en las mafias, su entorno social más íntimo se deteriora y la inseguridad y el sentimiento de desprotección lo asechan para adentrarlo cada vez más en la defensa de los ejércitos privados. Tanto Óskar Alexis como Luis reflejan la decadencia de los sectores más respetables de la sociedad y mientras En el cronista y el espejo conocemos de los oprobios, la traición y la venganza, en Cartas cruzadas, nos adentramos con detalle en las estrategias de los narcotraficantes para legalizar sus fortunas e insertarlas en la vida económica del país.

Para Daniel Pecaut, teniendo como telón de fondo la precariedad del Estado, es la economía de la droga la que provoca la consolidación de protagonistas dotados de recursos que les aseguran formas inéditas de influencia sobre la población y, al mismo tiempo, provistos de una capacidad ilimitada para trazar estrategias que toman en cuenta todos los efectos de sus acciones (2001:43).

La historia demostró que la economía de la coca era también un recurso en términos de capacidad de influencia social. Las FARC empezaron a garantizar el orden social y la protección económica a pequeños colonos coqueros y narcotraficantes. Pero no hay una influencia ideológica revolucionaria, sino una relación instrumental. Como instrumental fue la relación de las élites políticas con los narcos que financiaban sus campañas, e instrumental fue el surgimiento de los jóvenes sicarios que empezaron a asesinar por encargo en Colombia, principalmente desde la década de los años ochenta.

El sicariato en Medellín es tema central en La virgen de los sicarios, pero sin duda, Fernando Vallejo no se interesa en esta obra por profundizar en las causas que lo producen y redunda en una mirada externa y descreída que evidencia la nostalgia por una clase y una ciudad en decadencia. Vallejo construye a través de la reiteración de asesinatos injustificados y anodinos un tratamiento extremo e hiperbólico de la violencia urbana. A través de Fernando, un intelectual recién llegado a Medellín, Vallejo construye un relato provocador y desafiante de la tradicionalidad paisa. Fernando tiene un gusto homosexual casi cercano a la pedofilia y encuentra enAlexis yWilmar, dos jóvenes sicarios y prostitutos, una puerta de entrada para mostrarnos de cerca la criminalidad y la búsqueda del amor y compañía en medio de la desazón de la ciudad. Con el conocimiento del asesinato de Alexis por parte de Wilmar, Vallejo recurre a la venganza como reproductora histórica de la violencia. El sicariato en esta obra es un oficio normalizado de la sociedad anómica, ilegal pero legitimado en la subnormalidad. 
La anterior temática es común a Rosario Tijeras, la cual aborda el sicariato en Medellín; sin que el autor pertenezca a la marginalidad urbana, logra construir una novela con mayor detenimiento en los antecedentes de los personajes, el entorno social y familiar, las violencias que han padecido y las tensiones entre las clases sociales anómicas y normalizadas. Jorge Franco construye una novela clara, para la cual ha escogido como personaje principal a una mujer sicario. Esta aparente particularidad del género fue argumentada por el autor como una libertad poética propia de la literatura; sin embargo, resultaría una señal profética de la diversidad que lograría la violencia en Colombia, pues las mujeres empezaron a ser incorporadas como asesinas a las bandas criminales:

Estaban pagando un billete grande al que se bajara un tombo. A Ferney y a Johnefe los contrataron. Ferney no tenía buena puntería pero manejaba bien la moto, pero en cambio Johnefe era un águila, donde ponía el ojo ponía el pepazo. Después de que probaron finura los ascendieron, les empezó a ir muy bien, cambiaron de moto, de fierros y le echamos un segundo piso a la casa. Así si daban ganas de trabajar, todos queríamos que nos contrataran. A mí después también me reclutaron. (2006:73).

Rosario encarna la memoria histórica del joven subnormal, víctima de la violencia intrafamiliar, el abuso sexual y la exclusión social que encuentra en los grupos narcotraficantes un espacio para recuperar la autoestima y el respaldo de una figura de autoridad: es la oportunidad para "dejar de ser chichipato". Rosario cuenta a otro personaje el deseo de los jóvenes del barrio por empezar a trabajar con los patrones, por tener armas, motos y reconocimiento social ante vecinos y conocidos.

De otro lado, en referencia a la novela El sicario de Mario Bahamón Dussán, Óscar Osorio, sostiene que en ella se explora la marginalidad y la injusticia de los sectores populares, y se sustenta la tesis de que "la pobreza y la marginalidad engendran al sicario y este pierde en su ejercicio de muerte todo vestigio de humanidad” (2008).

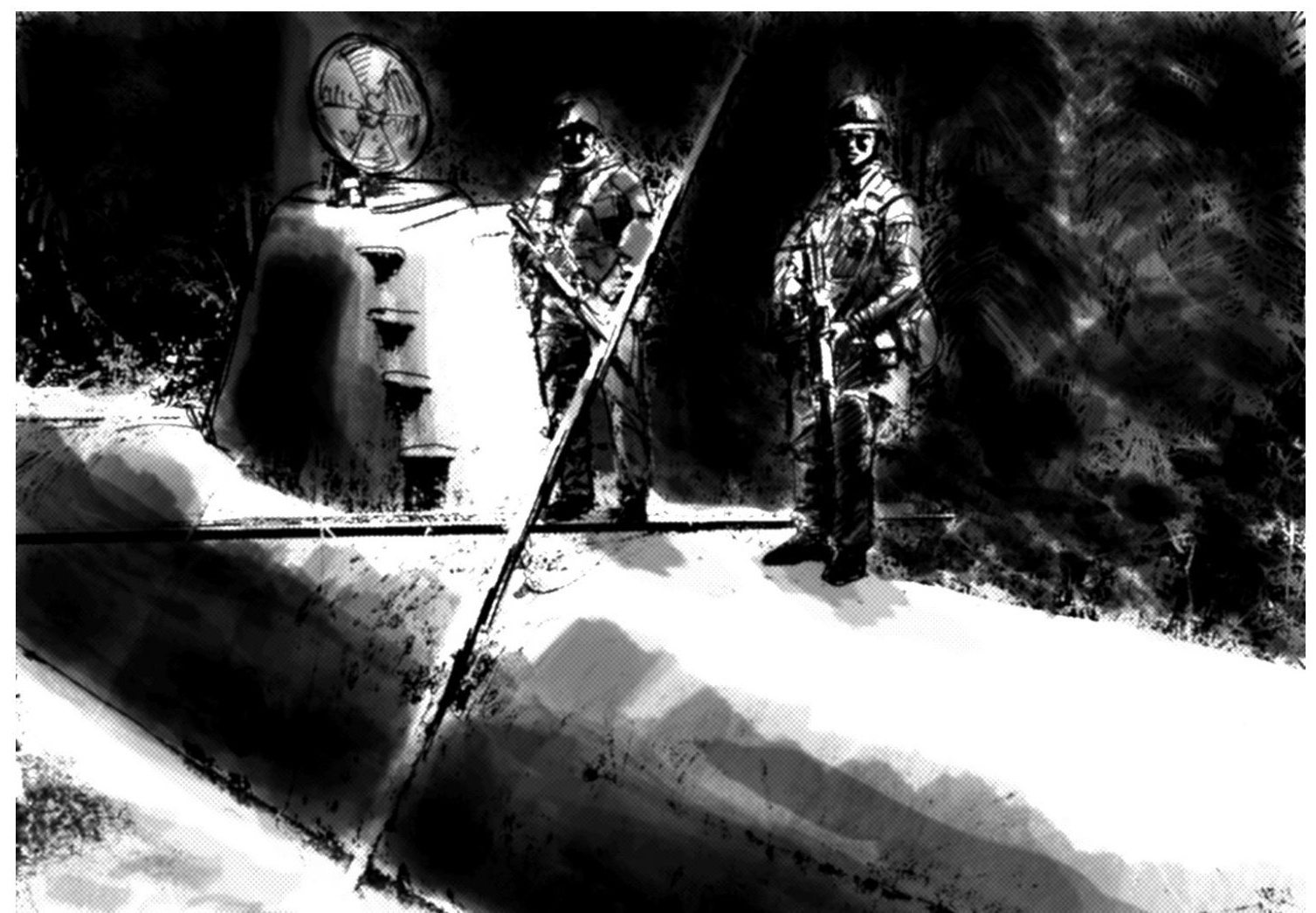


Un equilibrio entre los enfoques estructural e individual permite comprender que los jóvenes sicarios estaban insertos en una sociedad que impelía permanentemente por el crecimiento económico, sin propiciar las condiciones reales para que pudieran alcanzarlo. La tensión entre el contexto social y el carácter individual es abordada por el filósofo y escritor José Ortega y Gasset. Al respecto nos dice que "cuando se habla de nuestra vida, suele olvidarse que nuestra vida es en todo instante, y antes que nada, conciencia de lo que nos es posible. Si en cada momento no tuviéramos delante más que una sola posibilidad, carecería de sentido llamarla así. Sería más bien pura necesidad”. Más adelante nos dice que "tanto vale decir que vivimos como decir que nos encontramos en un ambiente de posibilidades determinadas. A este ámbito suele llamarse "circunstancias" o Mundo. Mundo es el repertorio de nuestras posibilidades vitales" (1998:14). En ese contexto los jóvenes de las comunas de Medellín tenían una expectativa vital sin mayores posibilidades, mundos cerrados y pletóricos de necesidades. El narcotráfico les ofreció la efervescencia de una nueva vida desbordada y sicarial.

Jorge Franco recrea la Medellín de la segunda mitad de los años ochenta, época en la que el cartel de esa ciudad se enfrascó en una guerra abierta contra el Estado, con el fin de evitar la extradición de nacionales. Y a pesar de que los sectores de menores ingresos seguían siendo las principales víctimas, ésta fue una época donde las élites dirigentes y las instituciones de poder empezaron a ser atacadas contundentemente ${ }^{2}$. Para Daniel Pecaut el éxito de Pablo Escobar ofrece el ejemplo de forzar al destino y el desprecio hacia el trabajo ordinario mal remunerado. Es determinante la influencia del narcotráfico en la violencia organizada semiestructurada de los ejércitos y la violencia generalizada vivida en las ciudades. Vemos en los años ochenta a narcotraficantes y sicarios participando del

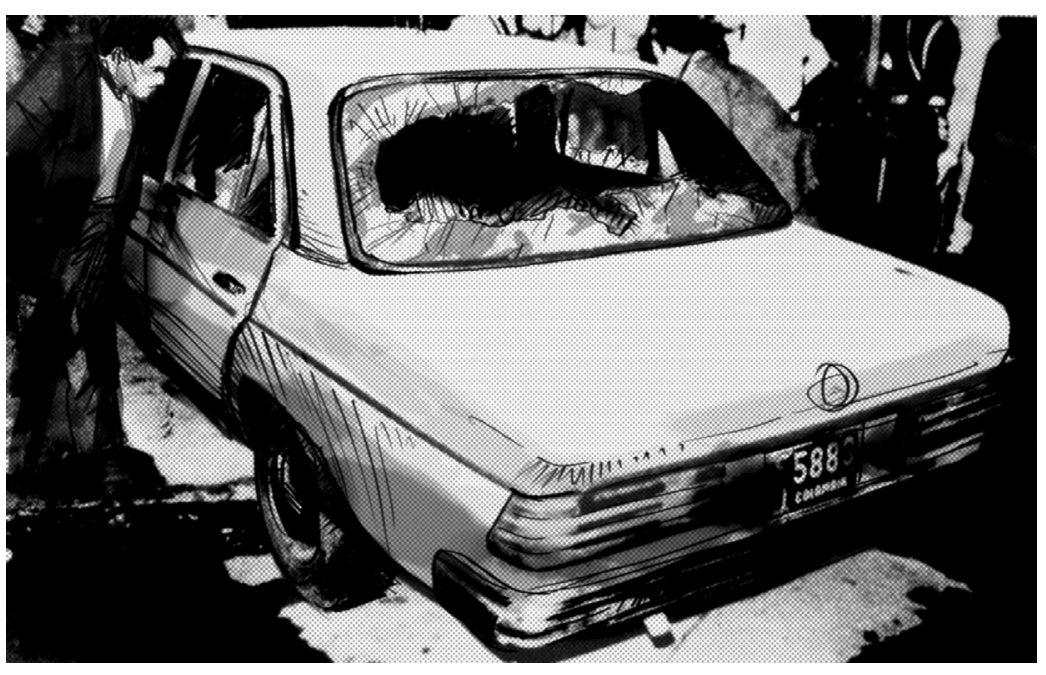
desarrollo del conflicto armado.

\section{Superando el estigma de la clase social}

Si bien el origen marginal y desgarrador como atributo central de la vida de los personajes sicarios tiene una altísima correlación con el hecho histórico, no se agota allí. En algunas provincias colombianas se empiezan a reconstruir con mayor detalle los relatos de jóvenes de clase media y alta que terminaron insertos en las dinámicas sicariales. No vivieron infancias marginales, ni padecieron carencias vitales, no son producto del analfabetismo o la ignorancia, tampoco se destacaron por la suntuosidad de los nuevos ricos, pero compartieron con la clase emergente la ambición por una fortuna desmesurada y rápida, la consecución de mayor poder económico. Integraron bandas criminales y también asesinaron a sueldo, pero tal parece que estos jóvenes poco pintorescos aún no se consideran en la narrativa de la violencia.

En Rosario Tijeras los personajes Antonio y Emilio viven seducidos por la exuberancia de Rosario, a la vez que se estremecen por el vértigo del submundo en que se desenvuelve. Sin embargo, nunca hacen parte de las prácticas del sicariato; se sumergen y degradan en las drogas seducidos por una mujer, no por la vida que ella ofrece. 
Para Pecaut "la expansión del narcotráfico es el punto de partida de la caída de Colombia en una situación de violencia generalizada, con efectos sobre la lucha armada, la crisis institucional (cuyo indicador más manifiesto es la corrupción), la desorganización del tejido social. Esto ha producido una amplia desorganización social que favorece toda clase de violencia” (2001:13). Este es el escenario que recrea Sergio Álvarez en La lectora. Con el argumento de que una mujer ha sido secuestrada para que lea un libro y descifre el destino de dos millones de dólares, el autor nos sumerge en una Bogotá decadente que padece múltiples formas de violencia.

Álvarez construye un relato del sicariato y la violencia urbana. En la obra vemos una Bogotá escindida, un escenario con seres consumidos entre las drogas y el hampa. En la historia se refleja el influjo de los habitantes de provincia hacia la capital y muchos terminan en bandas de secuestradores y prácticas criminales. A través de la lectura de la mujer secuestrada conocemos la historia de Karen, una prostituta condenada a perseguir la muerte en el camino de acompañar a Cachorro, su amor imposible, durante la consecución de dos millones de dólares.

Aunque este argumento es propio del cine norteamericano y algunas "salidas de emergencia” narrativas y algunas escenas estereotipadas, dan muestra de dicha influencia en el autor, alrededor de la anécdota del dinero, se construye un retrato de la decadencia, la desigualdad social, la corrupción y la marginalidad de una capital convulsionada.

Bogotá aparece como una ciudad estallada, sin dios y sin ley, y sus calles como el escenario de persecuciones entre sicarios, ajustadores de cuentas, "lavaperros" del narcotráfico y autoridades corruptas. Vemos la ciudad sobrepoblada que ha consolidado en su centro un barrio del despojo y la decadencia:

Paraíso de la clase baja del mundo criminal, el Cartucho aloja en sus calles y casas destrozadas toda clase de atracadores de poca monta, drogadictos terminales, prostitutas en decadencia, recolectores de desechos, niños narcotraficantes, policías corruptos, estafadores arruinados y sacerdotes y pastores de una veintena de iglesias. (65).

La novela construye la tesis de que el dinero del narcotráfico ha corrompido todas las estructuras sociales y ha llevado a actores de todo orden a establecer relaciones de mutuo beneficio que en ocasiones la mutua desconfianza y el incumplimiento van desencadenando en la violencia bogotana. Cachorro antes de morir destruye el dinero que ha desatado persecuciones, secuestros, crímenes y delaciones entre quienes lo perseguían. La muerte rápida y la pérdida del amor parecen los resultados finales.

Llama la atención el final, Karen el personaje principal del relato que leemos en La lectora, luego de presenciar la muerte de su amor imposible, se siente seducida por un destino incierto:

Durante el camino, en la mente de Karen se mezclaron de forma simultánea la cara muerta de Cachorro y la de una amiga que muchas noches le había hablado del Guaviare y que se extasiaba soñando con aquel lugar sin documentos de identificación ni antecedentes policíacos, donde el dinero de la coca era derrochado sin medida. (222). 
De esta forma comprendemos que Karen ha decidido sumergirse en otro escenario de violencia en busca de mejores condiciones económicas. Pecaut matiza las tesis que sostienen que la miseria se correlaciona directamente con la violencia y argumenta que el aumento de la criminalidad se dio en las regiones con mayores riquezas. Pecaut asegura que es la atracción de nuevos inmigrantes y la descomunal desigualdad en los ingresos de las regiones ricas las que propician los incrementos de la violencia. El Guaviare se convirtió en un foco de actores armados donde guerrilleros, pequeños narcotraficantes y paramilitares se trenzaron en disputa por el comercio de la cocaína. Este escenario pone de manifiesto la precariedad del Estado colombiano, su debilidad institucional y su incapacidad para ejercer la autoridad en grandes partes del territorio. "Colombia a lo largo de los siglos XIX y XX, ha sido un país de colonización no controlada” (2001:163).

Como vemos, las novelas aquí mencionadas han logrado construir una memoria diversa de nuestros tiempos donde la soberanía de la fuerza bruta es el valor preponderante de nuestro país. Con la expansión de la economía de la droga y luego de la transición del tráfico de marihuana al de la cocaína, entre 1980 y 1995, el número de los muertos de todo origen superó los 300.000 (Pecaut, 2001:38). En todas las obras abordadas, con mayor o menor medida, es clave la economía de la droga, el narcotráfico y sus prácticas asociadas.

Este es el escenario dispuesto para que Héctor Abad Faciolince construya en Angosta una ficción prospectiva de la Colombia actual. En la obra el autor lleva al extremo la exclusión social y Angosta es una ciudad estrictamente separada por tres sectores, tres clases sociales y tres climas. En esta obra la violencia del narcotráfico y el sicariato son una expresión más de múltiples mixturas de violencias que convergen en la ciudad. La dirigencia política ha reglamentado la marginación a través de la Política de Apartamiento, logrando restringir legalmente la libertad de las personas:

Desde hace treinta y dos años Angosta no es una ciudad abierta; nadie está autorizado a desplazarse libremente por sus distintos pisos. Al principio esta regla era tácita y cada casta permanecía en su gueto, más por costumbre o cautela que por obligación. Pero cuando arreciaron los atentados terroristas, a finales de siglo, las tropas de los países garantes acordonaron la zona, y la ciudad fue dividida, con nítidas fronteras, en tres partes: el Sektor F, correspondiente al llano de Paradiso, en Tierra Fría, con paso restringido; el Sektor T, el verdadero centro de Angosta, a todo lo largo del estrecho valle del Turbio, en la antigua zona cafetera; y el Sektor C, en algunas laderas de la orilla occidental del río, en Tierra Templada, pero sobre todo al pie y

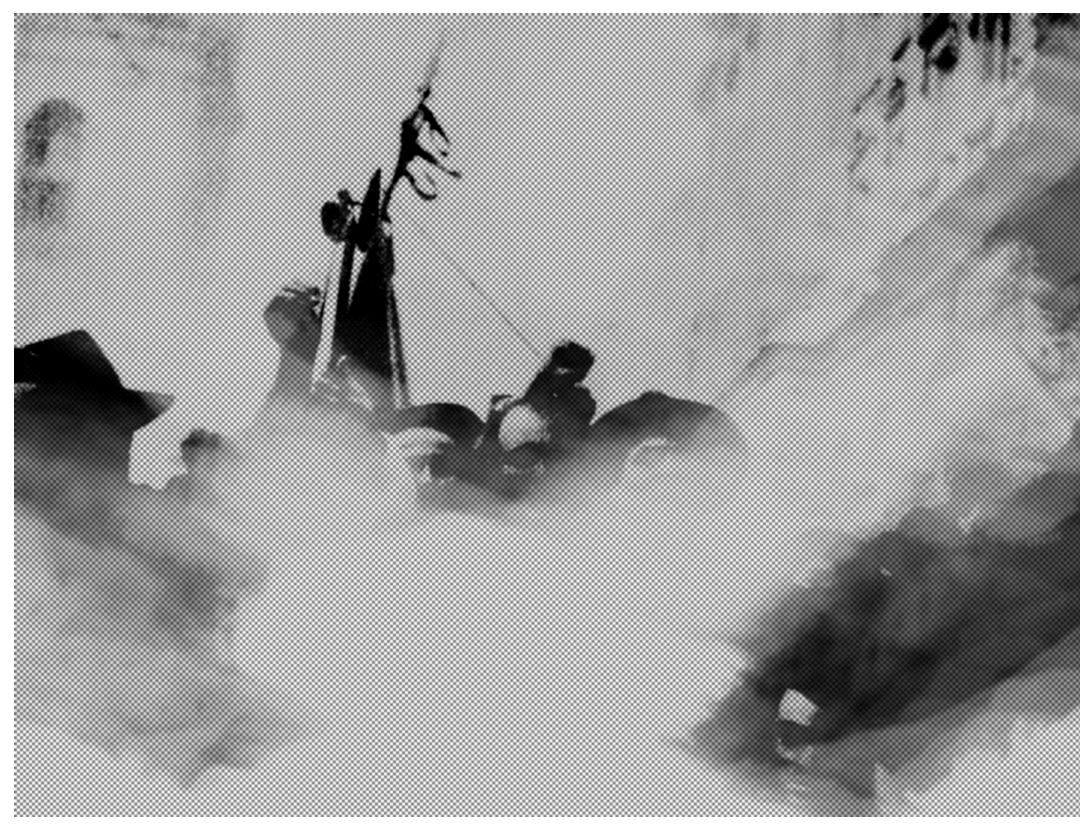
alrededor del Salto de los Desesperados, en Tierra Caliente. (2003:24). 
Sin duda, Faciolince construye en un universo ficcional propio un retrato hiperrealista de nuestros tiempos. Cimienta personajes memorables, llenos de matices y detalles, que además de padecer la violencia, se debaten entre la tristeza, la desazón, el vértigo, la soledad, la búsqueda de una precaria felicidad y sentido de vida. En Angosta El salto de los desesperados es el lugar destinado para desaparecer a los muertos, mientras el río Turbio, ofrece el caudal por donde se les puede ver pasar. La novela destaca con ironía la vana nobleza de los “Dones” y sus escenarios más oscuros. También la forma como ingresan a los sectores pobres, acompañados de escoltas en carros blindados, mientras los Segundones se someten a la indignidad legalizada mediante el Chek point:

“-¿Usted es un segundón, no?

-Sí, así nos dicen. (Andrés Zuleta)

...-¿Alguna vez se ha dedicado a actividades terroristas o ha pertenecido a grupos declarados ilegales por el gobierno?

...ंTiene alguna enfermedad infecto-contagiosa, sida, paludismo, fiebre amarilla, tuberculosis, sífilis, hepatitis B, gonorrea?

...-¿Tiene algún desorden mental, consume drogas o es adicto a alguna sustancia prohibida?

...-¿Pretende quedarse ilegalmente en Tierra Fría?"

(2003:21).

Con el posterior asesinato de Andrés Zuleta, un noble y sensible escritor, vemos como la violencia ha cobrado todo tipo de víctimas y sentimos el dolor ante su deceso. En Angosta un suprapoder llamado los Siete Sabios decide sobre la vida de las personas y declara como enemigo a todo aquel que atenta contra la exacerbada exclusión, legalizada mediante la Política de Apartamiento, incluyendo entre sus víctimas al presidente de la Fundación $\mathrm{H}$, una institución filantrópica que condena la marginación.

Para Pecaut "La diferencia entre violencia organizada y violencia desorganizada no queda totalmente suprimida, pero la mutua resonancia entre ambas conduce a la violencia generalizada, que cruza tanto las relaciones sociales como las relaciones interindividuales, influyen tanto sobre el funcionamiento institucional como sobre los valores sociales" (2001:195).

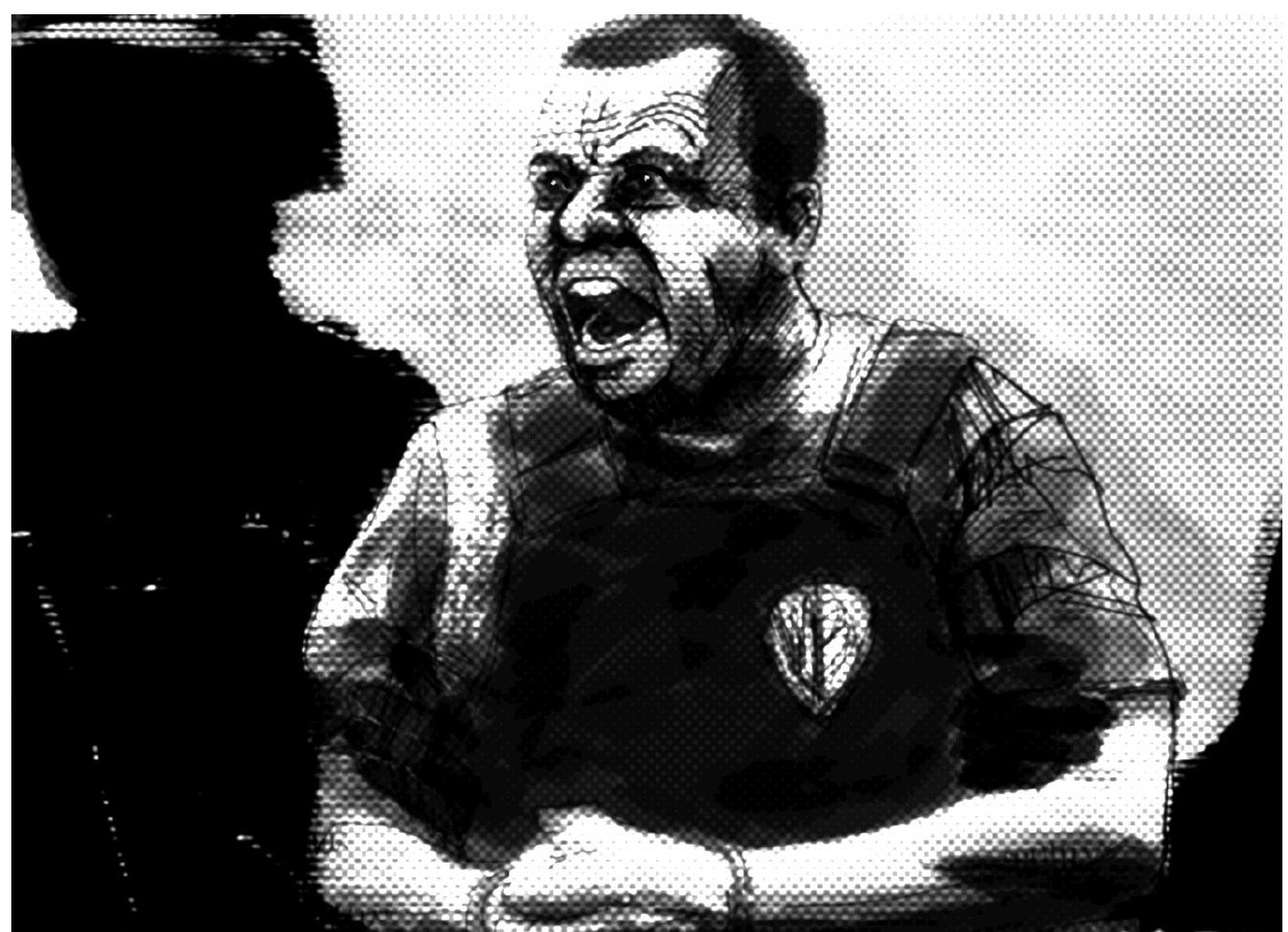


Es Angosta una metáfora compleja y profunda de Bogotá y de otras capitales colombianas. En ella sólo prevalece la hegemonía del dinero y un millón de dólares, sin importar su origen, representa la distinción social. En la ciudad converge la violencia del ejército, los grupos paramilitares (Secur), las acciones conjuntas entre ambos y, por supuesto, la guerrilla. En Angosta la delincuencia está asociada públicamente con la pobreza y, por ende, son los pobres las principales víctimas. En la ciudad vemos a los mafiosos como el Putas y el Señor de las Apuestas legalizando los dineros ilícitos en instituciones tradicionales y disponiendo a su antojo la vida de las personas. En Angosta se asesinan sindicalistas y en medio de la atrocidad palpante, medios de comunicación como Pujanza, operan como Aparatos Ideológicos Informativos que legitiman el "emprendimiento" de la clase dirigente.

La historia de Colombia ha normalizado una complementariedad entre el orden y la violencia. Las obras aquí abordadas así lo demuestran, construyen una memoria trágica y desesperanzada de nuestros tiempos, un testimonio de lo que hemos vivido. La precariedad del Estado, la debilidad de sus instituciones, la banalización de la violencia y su naturalización, desatada por la expansión de la economía de la droga y propiciada por ilegitimidad estatal nos han sumido en una guerra compleja, paulatinamente desideologizada donde la población sigue siendo la principal víctima. Por su parte, los escritores aquí abordados, con mayor y menor acierto, han hecho un importante trabajo por ficcionalizar nuestras historias y por hospedarlas en relatos para la memoria colectiva de nuestra nación.

Una futura narrativa de la violencia podría indagar el destino de los desmovilizados y su implicación en el incremento de la violencia urbana. Jóvenes mercenarios, ex militantes de los ejércitos, con bajos niveles de escolaridad y con la experiencia de la violencia como el principal capital para la subsistencia. Tal como ocurrió en El salvador, después de la desmovilización del Frente Farabundo Martí para la Liberación Nacional (FMLN), la incorrecta incorporación de miles de jóvenes mercenarios en las ciudades podría disparar aún más los índices de violencia urbana. Escenarios dispuestos para el mantenimiento de la soberanía de la fuerza bruta. 


\section{Notas}

1 Menciono como período de la "Violencia" los años entre 1946-1965. Aunque no existe un consenso sobre las fechas, me acojo a la propuesta de Oscar Osorio en su ensayo "Anotaciones para un estudio de la novela de la Violencia en Colombia” (revista Poligramas N.19. Escuela de Estudios Literarios). En 1946 se da el ascenso del partido Conservador al poder, lo que dio inicios al conflicto partidista y 1965 marca la aparición de las guerrillas modernas y la desaparición y transformación de las guerrillas liberales.

2 Las mafias narcotraficantes libraban una guerra a muerte con el Estado y los coletazos de los diálogos con las guerrillas acapararon la atención política del país. A manera de un breve sumario la historia recuerda una serie de hechos que bien merecen sus propias investigaciones: los narcos asesinaron al Ministro de Justicia Rodrigo Lara Bonilla, en 1985 el M-19 se tomó el Palacio de Justicia, el 5 de enero de 1985 el gobierno extraditó los primeros cuatro colombianos, en 1986 extraditó 28 más. La noche del 17 de diciembre de 1986 los narcos asesinaron a Guillermo Cano, director de El Espectador, el 18 de enero de 1988 los Extraditables secuestraron a Andrés Pastrana, candidato conservador a la alcaldía de Bogotá; el 25 de enero asesinaron al procurador Carlos Mauro Hoyos y el 18 de agosto de 1989 al comandante de la policía de Antioquia, Coronel Waldermar Franklin Quintero y al candidato presidencial Luis Carlos Galán. El 25 de septiembre de 1989 fue volado por un carrobomba el periódico El Espectador y el 16 de octubre el diario Vanguardia Liberal de Bucaramanga. Entre 1987 y 1990 fueron asesinados cuatro candidatos presidenciales: Jaime Pardo Leal y Bernardo Jaramillo de la Unión Patriótica, Carlos Pizarro, líder del M-19 y Luis Carlos Galán, candidato oficial del Partido Liberal. Entre 1989 y 1990 fueron asesinados más de quinientos policías en Medellín, explotaron 60 carros bomba en las capitales y derribaron un Jet de Avianca con 109 pasajeros en pleno vuelo.

\section{Referencias}

Abad Faciolince, Héctor. (2007) Angosta. Bogotá: Planeta Colombiana.

Álvarez Gardeazábal, Gustavo. (1986) El Divino. Bogotá: Círculo de lectores.

Álvarez, Sergio. (2006) La lectora. Bogotá: Punto de lectura.

En qué momento se jodió Medellín. Varios autores. (1991) Editorial Oveja Negra.

Escamilla, Oscar. (2002). Narcoextravagancia. Historias insólitas del narcotráfico. Editorial Aguilar.

Franco, Jorge (2003). Rosario Tijeras. Bogotá: Casa editorial El Tiempo.

García, Kevin. (2007). Fuego en las venas. Duelo y dolor en Cartago. Tesis de Pregrado. Escuela de Comunicación Social.

Guizado, Camacho Álvaro, Andrés López Restrepo y Francisco E. Thoumi. (1999). Las drogas, una guerra fallida, visiones críticas. Tm editores. Bogotá.

Jaramillo Agudelo, Darío. (1995) Cartas cruzadas. México, D.F.: Ediciones Era.

Ortega y Gasset, José. (1998). La rebelión de las masas. Ediciones Drake. Medellín.

Osorio, Oscar. (2004). Angosta y el ancho caudal de la violencia colombiana. En Poligramas, 22. Cali:

Escuela de Estudios Literarios, Universidad del Valle. . (2008). El sicario en la novela colombiana. Texto producto de la investigación Violencia del narcotráfico y el sicariato en la novela colombiana. Universidad del Valle. (2008). El cronista y el espejo. Universidad del Valle.

Pardo Rueda, Rafael. (2004). La historia de las guerras. Editorial Vergara. Bogotá.

Pecaut, Daniel. (2004) Memorias en conflicto: aspectos de la violencia política contemporánea. Edita: Lima:

Embajada de Francia - Instituto de estudios peruanos. IEP - Institut français d'études andines.

IFEA - Red para el desarrollo de las ciencias sociales en el Perú. . (2001). Guerra contra la sociedad. Bogotá, Editorial Planeta.

Saer, Juan José. (1997). El concepto de ficción. Argentina: Grupo Editorial Planeta.

Restrepo, Laura. (2006). Leopardo al sol. Bogotá: Alfaguara.

Vallejo, Fernando. (2002). LaVirgen de los Sicarios. Bogotá: Alfaguara. 